\title{
Molecular Structure Problem
}

National Cancer Institute

\section{Source}

National Cancer Institute. Molecular Structure Problem. NCI Thesaurus. Code C92121.

Problems related to the presence of an inappropriate molecular geometry somewhere in the device (i.e. the spatial arrangement of atoms in a molecule and the chemical bonds that hold the atoms together). 